\title{
Síndrome de Werner Associada a Quadro Esclerodermiforme: Relato de Caso e Revisão da Literatura
}

\section{Werner's Syndrome Associated with Scleroderma-Like Syndrome: Case Report and Literature Revision}

\author{
Cristiane Kayser ${ }^{(1)}$, Sandro F. Perazzio ${ }^{(2)}$, Flávia S. Machado(2), Luís Eduardo C. Andrade ${ }^{(3)}$
}

\section{RESUMO}

A síndrome de Werner é uma doença autossômica recessiva rara associada a envelhecimento precoce, cujo quadro cutâneo deve ser distinguido daquele encontrado na esclerose sistêmica (ES). Descrevemos aqui o caso de uma paciente de 39 anos de idade, portadora de síndrome de Werner, encaminhada ao nosso serviço com hipótese diagnóstica inicial de ES. A paciente apresentava várias manifestações associadas à síndrome de Werner, incluindo cabelos precocemente grisalhos, voz estridente, baixa estatura, alterações cutâneas esclerodermiformes, diabetes melito, catarata, hipogonadismo, hipotireoidismo e hiperlipidemia. Não apresentava fenômeno de Raynaud, manifestações viscerais típicas da ES, alterações capilaroscópicas periungueais ou auto-anticorpos. O diagnóstico de síndrome de Werner, apesar de raro, deve ser lembrado no diagnóstico diferencial de ES, principalmente na presença de manifestações atípicas e na ausência de alterações típicas da ES.

Palavras-chave: síndrome de Werner, esclerose sistêmica, síndromes progeróides, escleroderma.

\section{INTRODUÇÃO}

A síndrome de Werner é uma doença autossômica recessiva rara associada a envelhecimento precoce, cujo quadro cutâneo pode simular o espessamento cutâneo característico da esclerose sistêmica (ES). Foi reportada pela primeira vez em 1904 por Otto Werner, que descreveu quatro membros de uma mesma família com quadro sugestivo de esclerodermia, catarata e sinais de envelhecimento precoce. Desde então, aproximadamente mil casos de síndrome de Werner foram descritos em todo o mundo, porquanto $75 \%$ são descritos em japoneses ${ }^{(1)}$.

\begin{abstract}
Werner's syndrome is a rare autosomal recessive disease associated with premature ageing. Skin alteration must be distinguished from cutaneous manifestation of systemic sclerosis (SSc). We describe a case of a 39 years old patient with Werner's syndrome admitted with an initial diagnostic hypothesis of SSC. The patient had many characteristic features associated with Werner's syndrome including gray hair, hoarseness, short stature, scleroderma-like skin changes, diabetes mellitus, cataracts, hypogonadism, hypothyroidism, and hyperlipidemia. There was no Raynaud's phenomenon, other typical visceral manifestation of SSc, nailfold capillary alterations or autoantibodies. Werner's syndrome diagnosis notwithstanding rare, should be remember in the differential diagnosis of SSc, mainly in the presence of atypical manifestations and in the absence of typical features of SSc.
\end{abstract}

Keywords: systemic sclerosis, werner syndrome, progeroid syndromes, scleroderma.

Pacientes com síndrome de Werner apresentam uma série de sinais e sintomas similares ao envelhecimento em estágios precoces de suas vidas (aparência senil, alopecia precoce ou cabelos precocemente grisalhos). Apresentam geralmente também alterações cutâneas (hiperqueratose, pele esclerótica ou atrófica), catarata, aterosclerose, diabetes melito tipo 2 (DM2), hipogonadismo e risco aumentado para o desenvolvimento de neoplasias ${ }^{(2,3)}$. Descrevemos aqui o caso de uma paciente portadora de síndrome de Werner encaminhada ao nosso serviço com hipótese inicial de ES.

Recebido em 11/12/2007. Aprovado, após revisão, em 14/1/2008. Declaramos a inexistência de conflitos de interesse.

Disciplina de Reumatologia, Escola Paulista de Medicina/Universidade Federal de São Paulo (EPM/UNIFESP).

1. Médica doutora associada da disciplina de Reumatologia da EPM/UNIFESP, responsável pelo Ambulatório de Doenças do Espectro da Esclerose Sistêmica.

2. Médico(a) residente da disciplina de Reumatologia da EPM/UNIFESP.

3. Professor adjunto livre docente da disciplina de Reumatologia da EPM/UNIFESP.

Endereço para correspondência: Cristiane Kayser, Rua Botucatu, 740, $3^{\circ}$ andar, CEP 04023-062, São Paulo, SP, e-mail: criskayser@terra.com.br 


\section{RELATO DE CASO}

Paciente do sexo feminino, 39 anos, branca, natural e procedente de Suzano (SP), encaminhada para o Ambulatório de Esclerose Sistêmica da Disciplina de Reumatologia da Escola Paulista de Medicina/Universidade Federal de São Paulo (EPM/UNIFESP) para avaliação. Paciente com história de espessamento cutâneo de face e extremidades desde os 29 anos de idade e cabelos que se tornaram grisalhos desde os 13 anos. Aos 30 anos foi feito diagnóstico de DM2 e hipotireoidismo para os quais iniciou tratamento com levotiroxina $75 \mu \mathrm{g} /$ dia e hipoglicemiante oral, sendo que posteriormente foi introduzida também insulina. Referia, porém, difícil controle do DM. Há quatro anos vinha apresentando piora do espessamento cutâneo de face e extremidades e disestesia bilateral progressiva de membros inferiores, atribuída à neuropatia diabética. Há cerca de dois anos iniciou também quadro de dores em região plantar dos pés e picra progressiva da disestesia de membros inferiores, o que dificultava a sua deambulação. Negava fenômeno de Raynaud, eritema malar ou fotossensibilidade, pirose, disfagia, tosse, dispnéia, artralgia ou artrite, fraqueza muscular ou alterações do hábito intestinal. Além do DM e do hipotireoidismo apresentava antecedente de glaucoma há dois anos, cirurgia de catarata bilateral há um ano, e dislipidemia há cinco anos. Apresentava também história de amenorréia desde os 29 anos, razão pela qual recebeu diagnóstico de falência ovariana precoce e iniciou terapia de reposição hormonal. No momento vinha em uso de insulina NPH 46/30/28 UI, AAS $200 \mathrm{mg} / \mathrm{dia}$, captopril $25 \mathrm{mg}$ de $8 / 8$ horas e levotiroxina $75 \mu \mathrm{g} /$ dia. Antecedentes familiares: pais consangüíneos (primos de primeiro grau). Possui 11 irmãos (7 homens, 4 mulheres), sendo duas já falecidas, uma que teve diagnóstico de ES, falecida de AVC hemorrágico aos 48 anos e a outra falecida de melanoma com 45 anos. As duas irmãs falecidas, e um irmão ainda vivo, apresentavam fenótipo semelhante ao da paciente; o irmão se recusou a cc.nparecer em nosso serviço para investigação. Os demais irmãos são hígidos.

Ao exame físico apresentava fácies envelhecida, cabelo ralo e hipopigmentado e voz estridente (Figura 1$)$. Peso = $54 \mathrm{~kg}$, altura $=1,55 \mathrm{~m}$. Apresentava espessamento cutâneo difuso de face, membros superiores e inferiores. $\mathrm{O}$ tronco era alargado e os membros afilados, com diminuição dos tecidos subcutâneo e muscular (Figura 2). Região plantar com calosidades e diminuição do coxim gorduroso. Não foi observado fenômeno de Raynaud, microcicatrizes ou úlceras em polpas digitais. Ao exame neurológico foi observada marcha pre-

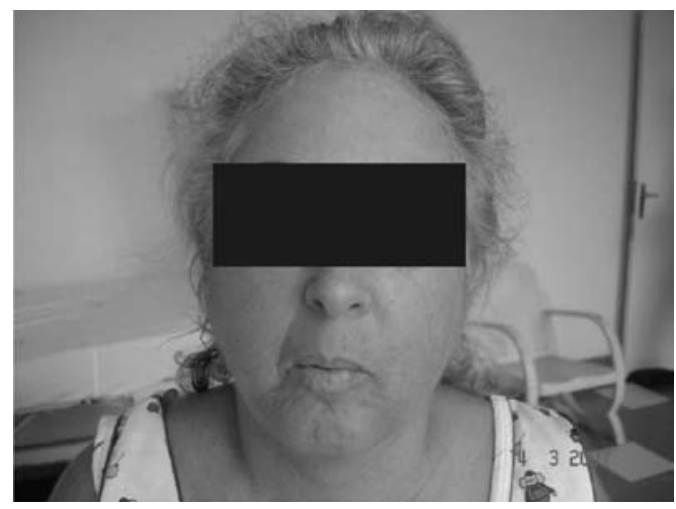

Figura 1 - Observam-se fácies envelhecida e angulada, e cabelo ralo e hipopigmentado.



Figura 2 - Observam-se o tronco alargado e os membros superiores e inferiores afilados.

judicada pela dor, alodínea intensa em ambos os membros inferiores, diminuição bilateral da sensibilidade tátil até 15 $\mathrm{cm}$ acima do joelho e da sensibilidade vibratória nos pés; a força muscular estava preservada e os reflexos profundos não puderam ser realizados por recusa da paciente. 
Os exames laboratoriais mostraram FAN em células HEp-2 l/160 pontilhado fino denso, anti-Scl-70 negativo e glicemia de jejum $469 \mathrm{mg} / \mathrm{dL}$. Exames hormonais mostraram níveis séricos diminuídos de LH, FSH, estradiol e progesterona, compatíveis com o período da pós-menopausa $(\mathrm{LH} 4,8 \mathrm{mUI} / \mathrm{ml}$; FSH 21,3 mUI/ml; estradiol $<20$ $\mathrm{pg} / \mathrm{nl}$; progesterona: $0,2 \mathrm{ng} / \mathrm{ml}$ ). A eletroneuromiografia dos quatro membros não mostrou alterações, porquanto não foi possível a avaliação de fibras tipo $\mathrm{C}$. A radiografia de pés evidenciou presença de calcificações em partes moles (Figura 3). Capilaroscopia periungueal, esofagograma, prova de função pulmonar, tomografia computadorizada de tórax e radiografia de mãos foram normais. A densitometria óssea não evidenciou osteoporose.

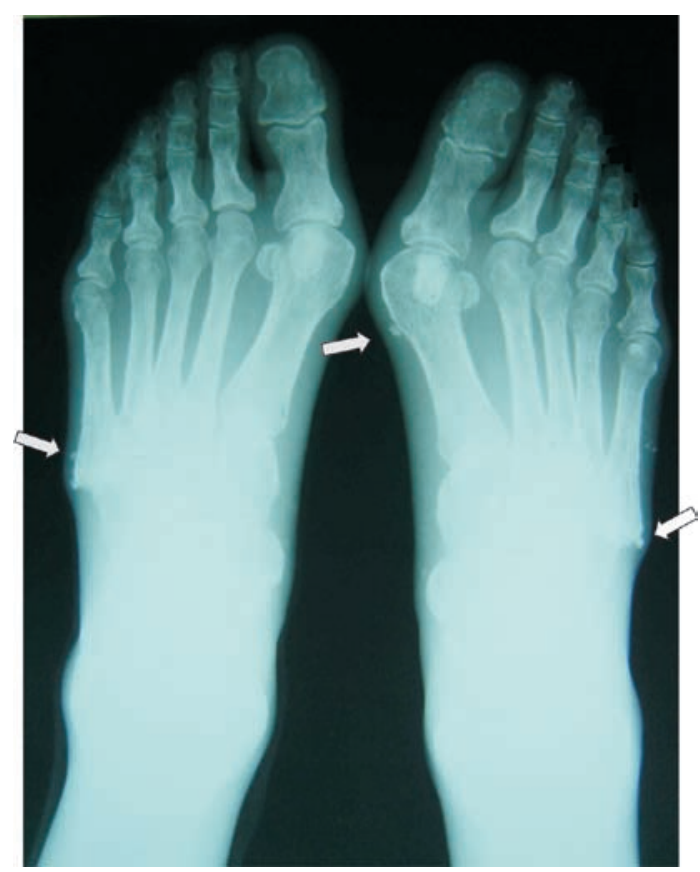

Figura 3 - Radiografia dos pés em AP demonstrando calcificações em partes moles (setas).

\section{DISCUSSÃO}

A síndrome de Werner é uma síndrome progeróide caracterizada por mutações no gene WRN, localizado no cromossomo 8pl2 e identificado como uma helicase tipo $\operatorname{Rec}^{(4)}$. Especial interesse no estudo de várias síndromes progeróides, como as de Werner e de Hutchinson-Gilford, tem surgido nas últimas décadas, já que estas simulam várias manifestações associadas ao envelhecimento natural e poderiam auxiliar na melhor compreensão dos mecanismos moleculares e biológicos envolvidos no envelhecimento. Um aspecto interessante, porém, é que em nenhuma dessas síndromes os pacientes apresentam todas as manifestações associadas ao envelhecimento natural, sendo chamadas de síndromes progeróides segmentais ${ }^{(5)}$. Além disso, diferenças qualitativas e quantitativas são observadas entre as síndromes progeróides e as manifestações do envelhecimento natural, por exemplo, em relação à extensão das alterações de coloração do cabelo em pacientes com síndrome de Werner e a associação dessas síndromes com neoplasias raras.

Clinicamente, a síndrome de Werner caracteriza-se por surgimento de envelhecimento precoce, associado a um fenótipo variável, com manifestações em múltiplos órgãos, como podemos observar no caso anteriormente descrito. Após infância e início da adolescência normais, os pacientes apresentam retardo e parada precoce no crescimento, seguidas pelo surgimento de uma série de alterações que costumam aparecer de maneira seqüencial: cabelos precocemente grisalhos e eventualmente alopecia, voz estridente, alterações cutâneas esclerodermiformes, catarata, DM, úlceras cutâneas, hipogonadismo, disfunção da tireóide, hiperlipidemia, osteoporose e aterosclerose ${ }^{(3)}$. Neoplasias, principalmente, as de origem mesenquimal, têm incidência aumentada. A alta incidência de malignidade pode ser explicada pela presença de instabilidade cromossômica descrita na doença ${ }^{(6)}$. O diagnóstico costuma ser feito em média aos 36 anos de idade. No entanto, a raridade desta doença pode dificultar ou retardar o diagnóstico. A expectativa média de vida é de 46 anos, sendo que as principais causas de óbito incluem doenças malignas, acidentes vasculares cerebrais e infarto agudo do miocárdio(3).

O diagnóstico clínico pode ser feito utilizando os critérios diagnósticos criados a partir de um registro internacional de pacientes com síndrome de Werner. Seis sinais principais e nove sinais e sintomas secundários são utilizados (Quadro 1$)^{(2,7)}$.

O diagnóstico molecular pode ser feito mediante genotipagem e identificação da mutação no gene $\mathrm{WRN}$, visto que 58 mutações no gene WRN já foram descritas em pacientes com síndrome de Werner ${ }^{(5,7,8)}$. O gene WRN, identificado em 1996, é um membro da família das helicases tipo RecQ que possui função catalítica e de exonuclease ${ }^{(4)}$. Todas as mutações associadas ao gene WRN conferem um fenótipo bioquímico comum: levam à desestabilização ou à perda da proteína WRN. A confirmação do diagnóstico por meio de métodos laboratoriais é indicada principalmente naqueles casos em que não haja história familiar convincente, em pacientes muito jovens ou com poucas manifestações da doença ${ }^{(5)}$. 
QuAdro 1

Critérios para diagnóstico de Síndrome de Werner

\begin{tabular}{l} 
Sinais e sintomas cardinais (início com idade maior que 10 anos) \\
1. Catarata bilateral \\
2. Pele característica (firme e atrófica, com alterações pigmentares, \\
ulcerações, hiperqueratose, atrofia subcutânea regional) e face \\
característica que foi descrita como em "forma de pássaro" (bird facies) \\
3. Baixa estatura \\
4. Pais consangüíneos (primos de terceiro grau ou mais próximos) \\
5. Cabelos esbranquiçados e finos prematuramente \\
6. Aumento nos níveis de ácido hialurônico em urina de 24 horas, \\
quando disponível \\
Outros sinais e sintomas \\
1. Diabetes melito \\
2. Hipogonadismo (hipodesenvolvimento sexual secundário, fertilidade \\
prejudicada, atrofia testicular ou ovariana) \\
3. Osteoporose \\
4. Evidência radiográfica de osteoesclerose das falanges distais dos dedos \\
das mãos e/ou dos pés \\
5. Calcificação de tecidos moles \\
6. Evidência de aterosclerose prematura (por exemplo, história de IAM) \\
7. Neoplasias mesenquimais (sarcomas), neoplasias raras ou múltiplas \\
8. Voz anormal (estridente, aguda ou rouca) \\
9. Pés planos \\
Diagnóstico: \\
Definitivo: Todos os sinais cardinais (o item 6 apenas se disponível) e \\
dois dos outros. \\
Provável: Os três primeiros sinais cardinais e dois dos outros. \\
Possivel: Catarata ou alterações dermatológicas e quaisquer outros quatro. \\
Exclusão: Início dos sinais e sintomas antes da adolescência. \\
\hline
\end{tabular}

Nakura et al., 1994.

A paciente descrita apresentava todos os sinais cardinais propostos por Nakura et al. (excluindo a dosagem de ácido hialurônico em urina de 24 horas) e ainda várias das manifestações secundárias da síndrome de Werner, como DM, hipogonadismo, pés planos e com perda do coxim gorduroso, calcificações de tecidos moles e voz estridente. Diabetes melito é encontrado em $44 \%$ a $70 \%$ dos pacientes e geralmente não é de difícil controle ${ }^{(2,9)}$. Entretanto, insensibilidade relativa à insulina, com conseqüente falta de resposta ao tratamento com insulina, é encontrada em pacientes com síndrome de Werner, o que poderia explicar a dificuldade no controle do DM no caso descrito.

Manifestações neurológicas ocorrem raramente nos pacientes com síndrome de Werner ${ }^{(10,11)}$. Chama a atenção no presente relato o quadro clínico de neuropatia periférica sensitiva apresentado. A eletroneuromiografia realizada em nosso serviço não mostrou qualquer alteração. No entanto, esse exame foi limitado pela não avaliação das fibras tipo $\mathrm{C}$, envolvidas na sensibilidade dolorosa e implicadas em sintomas, como disestesia e alodinia, como observado em nossa paciente. Alguns casos de neuropatia periférica em associação com a síndrome de Werner são descritos na literatura e, geralmente, afetam os nervos sensitivos. A patogênese da neuropatia periférica não é conhecida ${ }^{(10)}$. Muitos pacientes e a descrita, apresentam também DM, causa comum de neuropatia periférica, mas casos de neuropatia periférica são descritos também em pacientes sem $\mathrm{DM}^{(10,12)}$. Comprometimento do transporte axonal, característico do processo de envelhecimento, parece estar relacionado a esses $\operatorname{casos}^{(13)}$.

Uma série de manifestações cutâneas e musculoesqueléticas são descritas na síndrome de Werner, porquanto a principal diferenciação deve ser feita com a ES ${ }^{(14)}$. Alterações cutâneas esclerodermiformes são descritas em até 90\% dos casos. A manifestação cutânea que mais se assemelha a ES é a atrofia e a perda de tecido celular subcutâneo, o que confere aspecto semelhante ao encontrado em estágios tardios da ES. Esses achados são mais proeminentes nas extremidades e na face, sendo que o paciente adquire aspecto descrito como "face de pássaro" (bird facies), caracterizada por fácies angulada, afilamento nasal, espessamento cutâneo mais proeminente na região perioral e protusão dentária, alterações semelhantes às descritas em pacientes com ES. Hiperqueratose, calcificações subcutâneas e úlceras cutâneas ocorrem também com freqüência, e as úlceras são geralmente de difícil tratamento e podem infectar-se com freqüência ${ }^{(14,15)}$. Telangiectasias também podem estar presentes em pequena proporção dos pacientes com síndrome de Werner. Atrofia muscular, principalmente de membro inferiores, é descrita também em até 90\% dos casos. As enzimas musculares e a eletroneuromiografia não costumam apresentar alterações. Deformidades dos pés, caracterizadas principalmente por pés planos e ballux valgus são descritos em aproximadamente $30 \%$ a $40 \%$ dos casos $^{(14)}$. Deformidades mais graves dos pés, com alterações destrutivas e lesões osteolíticas são descritas em alguns casos e podem ser decorrentes de ulcerações crônicas com infecção secundária ${ }^{(14,16)}$. Osteoporose é descrita em $60 \%$ dos pacientes ${ }^{(3)}$.

Apesar de a síndrome de Werner poder apresentar-se com características clínicas semelhantes à ES, várias manifestações são distintas (Quadro 2). As manifestações cutâneas da síndrome de Werner costumam ter predileção pelos membros inferiores e pés, com acometimento menos grave da face, membros superiores e mãos. Ainda, na síndrome de Werner as úlceras costumam acometer novamente os membros inferiores e os pés, poupando as mãos. A esclerodactilia classicamente observada na ES, com endurecimento e edema, também não costuma estar 
presente na síndrome de Werner, em que a pele costuma apresentar mais freqüentemente aspecto de pele fina e firme ${ }^{(14)}$. Histologicamente, a pele de pacientes com síndrome de Werner mostra hiperqueratose, atrofia da derme e atrofia importante do tecido celular subcutâneo. Na pele de pacientes com ES, os achados histológicos mais importantes na fase aguda da doença são aumento no número de fibras colágenas, atrofia da epiderme, hialinização e fibrose das arteríolas e infiltrado mononuclear perivascular da derme e tecido celular subcutâneo ${ }^{(17)}$. Outra característica dos pacientes com síndrome de Werner é que os fibroblastos apresentam potencial replicativo reduzido em comparação com indivíduos saudáveis com a mesma idade ${ }^{(18)}$.

Quadro 2

ManifestaÇões da ES E da SÍNDRome de Werner

\begin{tabular}{lcc}
\hline & $\begin{array}{c}\text { Esclerose } \\
\text { sistêmica }\end{array}$ & $\begin{array}{c}\text { Síndrome de } \\
\text { Werner }\end{array}$ \\
\hline Alterações cutâneas & + & +++ \\
Pele atrófica & + & +++ \\
Atrofia do TCSC & & ++ \\
Hiperqueratose & - & +++ \\
Fácies angulada & ++ & + \\
Telangiectasias & +++ & +++ \\
Calcinose & ++ & +++ \\
Úlceras em membros inferiores & + & + \\
Úlceras digitais & +++ & - \\
Manifestações sistêmicas & & \\
Fenômeno de Raynaud & +++ & ++ \\
Envolvimento dos tratos gastrintestinal, & +++ & ++ \\
pulmonar e renal & & ++ \\
Catarata & - & \\
Desordens endocrinológicas & - & + \\
Envelhecimento precoce & - & - \\
Alterações laboratoriais & & + \\
Ácido hialurônico urinário & Normal & Aumentado \\
Alterações capilaroscópicas & +++ & - \\
Auto-anticorpos associados a ES & +++ & - \\
\hline
\end{tabular}

* Tecido celular subcutâneo.

Adaptado de Escalante et al., 1989(14)

\section{REFERÊNCIAS}

1. Goto M, Tanimoto K, Horiuchi Y, Sasazuki T: Family analysis of Werner's syndrome: a survey of 42 Japanese families with a review of the literature. Clin Genet 19: 8-15, 1981.

2. Epstein CJ, Martin GM, Schultz AL, Motulsky AG: Werner's syndrome a review of its symptomatology, natural history, pathologic features, genetics and relationship to the natural aging process. Medicine (Baltimore) 45: 177-221, 1966.
Além disso, os pacientes com síndrome de Werner não apresentam fenômeno de Raynaud, alterações capilaroscópicas periungueais e auto-anticorpos associados à ES. Tampouco apresentam as manifestações viscerais encontradas na ES, como dismotilidade esofageana, pneumopatia intersticial, hipertensão pulmonar e acometimento renal ${ }^{(14)}$.

Ainda, a síndrome de Werner, ao contrário da ES, é uma doença hereditária autossômica recessiva. A paciente descrita possuía forte história familiar: consangüinidade dos pais e três irmãos com fenótipo semelhante ao seu. Não conseguimos obter o prontuário médico da irmã já falecida que possuía diagnóstico de ES, mas é possível que, na verdade, a paciente fosse portadora também de síndrome de Werner. A outra irmã, com fenótipo semelhante, faleceu por melanoma, também descrito em freqüência aumentada nos pacientes com síndrome de Werner ${ }^{(6)}$.

A pesquisa de anticorpos contra antígenos celulares (FAN - fator antinúcleo) em células HEp-2 no caso descrito mostrou-se positiva com título de $1 / 160$ e padrão pontilhado fino denso. Presença de auto-anticorpos em baixos títulos é descrita em proporção considerável de pacientes com síndrome de Werner ${ }^{(3)}$. Deve-se ressaltar, porém, que a presença isolada de FAN positivo em teste de imunofluorescência indireta em células HEp-2 é encontrada em aproximadamente $15 \%$ da população saudável, a maioria desses indivíduos nunca desenvolverá uma doença auto-imune ${ }^{(19)}$. O padrão pontilhado fino denso encontrado no teste da paciente é um dos mais freqüentemente encontrados em indivíduos saudáveis com teste de FAN positivo.

A síndrome de Werner é uma doença associada a manifestações cutâneas parcialmente semelhantes à ES, e esses pacientes podem ocasionalmente consultar um reumatologista em razão das manifestações cutâneas e osteoarticulares. O diagnóstico de síndrome de Werner, apesar de raro, deve ser lembrado no diagnóstico diferencial de ES, principalmente na presença de manifestações atípicas para ES e na ausência de alterações típicas desta.

3. Goto M: Hierarchical deterioration of body systems in Werner's syndrome: implications for normal ageing. Mech Ageing Dev 98: 239-54, 1997.

4. Yu CE, Oshima J, Fu YH, et al.: Positional cloning of the Werner's syndrome gene. Science 272: 258-62, 1996.

5. Kudlow BA, Kennedy BK, Monnat RJ Jr.: Werner and Hutchinson-Gilford progeria syndromes: mechanistic basis of human progeroid diseases. Nat Rev Mol Cell Biol 8: 394-404, 2007. 
6. Salk D: Werner's syndrome: a review of recent research with an analysis of connective tissue metabolism, growth control of cultured cells, and chromosomal aberrations. Hum Genet 62:1-5, 1982 .

7. Nakura J, Wijsman EM, Miki T, et al.: Homozygosity mapping of the Werner syndrome locus (WRN). Genomics 23: 600-8, 1994.

8. Huang $S$, Lee L, Hanson NB, et al.: The spectrum of WRN mutations in Werner syndrome patients. Hum Mutat 27: 558-67, 2006.

9. Hauache OM, Pardini VC, Moisés RCS, Dib SA: Síndrome de Werner: aspectos clínicos e endocrinológicos. Arq Bras Endocrinol Metab 37: 187-95, 1993.

10. Anderson NE, Haas LF: Neurological complications of Werner's syndrome. J Neurol 250: 1174-8, 2003.

11. Sumi SM: Neuropathology of the Werner syndrome. Adv Exp Med Biol 190: 215-8, 1985.

12. Umehara F, Nakagawa M, Izumo S, Arimura K, Matsumuro K, Osame M: Werner's syndrome associated with spastic paraparesis and peripheral neuropathy. Neurology 43: 1252-4, 1993.
13. Malandrini A, Dotti MT, Battisti C, Federico A: Neurological involvement in Werner's Syndrome: clinical and biopy study of a familial case. Eur Neurol 44: 187-9, 2000.

14. Escalante A, Beardmore TD, Kaufman RL: Musculoskeletal manifestations of Werner's syndrome. Semin Arthritis Rheum 19:1-8, 1989.

15. Yeong EK, Yang CC: Chronic leg ulcers in Werner's syndrome. Br J Plast Surg 57: 86-8, 2004.

16. Jacobson HG, Rifkin H, Zucker-Franklin D: Werner's syndrome: a clinical-roentgen entity. Radiology 74: 373-85, 1960.

17. Seilbold JR: Scleroderma. In: Kelley WN, Ruddy S, Harris ED Jr., Sledge CB, editors: Textbook of rheumatology. 5.ed. Philadelphia-USA: WB Saunders Company, 1997.

18. Takeuchi F, Hanaoka F, Goto M, Akaoka I, Hori T, Yamada M, Miyamoto T: Altered frequency of initiation sites of DNA replication in Werner's syndrome cells. Hum Genet 60(4): 365-8, 1982.

19. Dellavance A, Leser PG, Andrade LEC: Análise crítica do teste de anticorpos antinúcleo (FAN) na prática clínica. Rev Bras Reumatol 47: 265-75, 2007. 